Reflexão \& Ação, Vol. 22, No 1 (2014).

\title{
Música Tradicional da Infância
}

\section{Entrevista com Lydia Hortélio, por Dulcimarta Lemos Lino.}

Breve currículo: Lydia Hortélio, personalidade vinculada à Música Tradicional da Infância no Brasil, criadora da Casa das Cinco Pedrinhas..., um lugar de Brinquedo, de vivência, pesquisa e documentação, estudo e irradiação de Cultura da Criança. Lydia Maria Hortélio Cordeiro de Almeida nasceu em Salvador/BA a 13 de outubro de 1932. Passou sua infância em Serrinha/BA, sertão da Bahia, é professora de Música, formação em Piano, Educação Musical e Etnomusicologia, estudos no Brasil, Alemanha, Portugal e Suíça. Dedica-se à pesquisa e documentação, estudo e difusão de Cultura da Criança e Cultura Popular, em particular as Manifestações Musicais da zona rural do município de Serrinha/BA. Tem participado de várias experiências em Educação, buscando favorecer a inteireza e o movimento da Criança e despertar desde a Infância uma consciência de BRASIL.

Dulcimarta Lemos Lino - 1) Para iniciar nossa conversa gostaria de escutar sobre tua infância, tuas memórias sonoras. Como te encontraste com a Música quando Criança?

Lydia Hortélio - Meu encontro com a Música se deu desde muito tenra idade, através das Cantigas de Ninar e Histórias Cantadas que ouvia de minha mãe, dos Brinquedos Cantados, intensamente praticados entre as Crianças de Serrinha daquele tempo, além dos Romances e Cantigas de Samba que ouvia de meu pai, homem do Sertão, que batucava na mesa com a colher, e dançava com muita alegria a qualquer hora do dia... Mais tarde veio juntar-se à minha experiência musical infantil o repertório da querida "Filarmônica 30 de Junho", a Banda de Música de Serrinha, que animava nossas tardes de domingo no Coreto da Praça e acompamhava, infalivelmente, todas as festas religiosas e civís de nossa cidade. Composta atualmente de Crianças e Jovens, a centenária "30 de Junho" continua muito atuante, mantendo uma Escola de Música e exercendo significativa ação cultural na região. 
Dulcimarta Lemos Lino - 2) Como e por que a opção pelo encontro entre Música e Educação da Infância?

Lydia Hortélio - Além de uma predisposição inata, acho que foi essencial para a escolha de um destino na Música, o fato de ter tido experiências musicais significativas desde muito cedo. Através dos relatos da família, vim, a saber, que desde muito pequena gostava de cantar, e ainda me lembro, era atraída por toda manifestação musical e buscava expressão na Música muito naturalmente, organizando "teatros" e apresentações musicais com outras Crianças. Comecei a ter aulas de Piano ainda menina e posteriormente escolhi este instrumento como centro de minha formação musical. Mais tarde me dediquei a estudos de Etnomusicologia e Educação Musical, na busca de compreensão dos fenômenos musicais do nosso Povo e de uma Educação Musical fundada na Cultura Brasileira.

Dulcimarta Lemos Lino - 3) A partir da experiência de pesquisa e documentação de tantas cantigas, brincadeiras e expressões das Crianças no Brasil e ao redor do mundo em diferentes períodos históricos, como descreverias as narrativas expressas pelos brinquedos sonoros?

Lydia Hortélio - Os Brinquedos Cantados, os Brinquedos Ritmados, ou seja, a MÚSICA TRADICIONAL DA INFÂNCIA, a MÚSICA DA CULTURA INFANTIL, integra fatos culturais que estão na base da Cultura de um Povo, portanto, no berço da CULTURA BRASILEIRA, carregando em seu cerne os arquétipos da língua, da música, o movimento próprio de nossa Alma Ancestral, sua maneira de ser particular, sua graça e poder diáfano.

Dulcimarta Lemos Lino - 4) Wisnik (2004) ${ }^{1}$ afirma que a Música Brasileira é uma "colcha de recados", pedaços de sons enredados em uma miríade vetorial de expressões. Que "recados" identificas em teu trabalho como educadora?

Lydia Hortélio - A afirmação de Wisnik é muito procedente. Precisamos escutar estes recados! E imaginar além..., investigando as estruturas e princípios que regem a linguagem, os elementos de origem, a dinâmica de desenvolvimento, o "tom" particular de cada

\footnotetext{
${ }^{1}$ WISNIK, José Miguel. Sem receita: ensaios e canções. São Paulo: Publifolha, 2004.
} 
manifestação, "os pedaços de sons enredados...", enfim, procurando sentir e compreender o fenômeno musical brasileiro em extensão e profundidade, buscando inclusive novas transposições, desdobramentos, e uma prática criadora que levará a uma ampliação crescente o nosso vasto e diferenciado patrimônio musical.

É preciso fincar no BRASIL as raízes dos nossos filhos! Este processo se inicia com o leite materno, com as primeiras palavras, as primeiras cantigas. São elas que inauguram os sentidos e fazem vibrar o coração menino... É bom que ele seja tocado pelo gesto de origem, a poética natural, o caráter, o fraseado, o ritmo, os acentos, as formas, o movimento próprio, os arquétipos da Cultura Brasileira.

Fernando Pessoa dizia: “A língua é a Pátria”! Creio nisto. Daí a necessidade de exercitarmos a Língua desde muito cedo. Não se trata, naturalmente, do jargão da mídia, antes, porém, do exercício da língua mãe, da língua mãe musical, aquela que os nossos Cantadores e Poetas Populares ainda conhecem, dá corpo às Cantigas de Ninar e a toda a Música Tradicional da Infância, e é onipresente no vasto repertório poético de nossas manifestações populares.

Dulcimarta Lemos Lino - 5) Qual o papel do pedagogo e do Professor de Música no processo de recuperação da compreensão da Criança a partir de seu próprio movimento espontâneo: o brincar com sons?

Lydia Hortélio - O papel do pedagogo e do Professor de Música seria, justamente, não ser “pedagogo", tão pouco "professor"! No meu entender, é preciso, antes de mais nada, gostar de MÚSICA, de BRINCAR... , ter encantamento por MENINO, pela CULTURA DA CRIANÇA, e conhecer um vasto repertório de MÚSICA TRADICIONAL DA INFÂNCIA, inclusive os Brinquedos da Cultura Infantil contemporânea, tão expressiva, de linguagem de movimento altamente diferenciada.

É preciso descobrir novas formas de convívio, perspectivas de contato inteligente que resultem em verdadeiro ENCONTRO! Quem aprende, o que, com quem, onde?! A ALEGRIA é fundamental, im - pres - cin - dí - vel! Re-conhecer-se CRIANÇA, afirmar a VIDA, BRINCAR... Este seria o chão, o começo... O resto?! Isto vem!

E o espaço de NATUREZA precisa ser considerado. Vivemos uma artificialidade paralisante, nada sensível, tão-pouco inspiradora. Mas uma revolução está a caminho! Em breve nada poderá se manter, se não partir do movimento DENTRO... Dali partiremos, 
deixando que a CRIANÇA nos tome pela mão e nos conduza. Muitos já têm vislumbres: saudades do Futuro... Talvez estejamos mais perto da ALEGRIA do que imaginamos! É preciso levar nossas Crianças para a NATUREZA. Ela tem o poder de provocar o movimento contido fundo, alto, longe... perto! A ALEGRIA virá insinuar-se, o riozinho começar a correr... E então, será natural cantar uma cantiga, mover-se com verdade, dizer uma palavra essencial. Ela pode vir do desenho de uma árvore, do caráter de um animal, da graça e do rítmo de uma formiguinha, do cheiro de uma folha, do azul do céu, da brisa que passa, do barulho do mar..

Estamos mergulhados em mecanicismo temerário, disfarçado em Cultura, Arte, Ciência, Modernidade... , do qual precisamos nos libertar. É necessário escutar para DENTRO, aprender a discernir, e inaugurar o MUNDO NOVO!

Florescer é a palavra de ordem! A cada um o seu jardim... Os caminhos são todos, a hora é agora, e a ALEGRIA, a pedra de toque...

Dulcimarta Lemos Lino - 6) Em tempos de obrigatoriedade do ensino de Música nas escolas brasileiras, como o repertório de vivências da Música Tradicional da Infância pode contraporse ao engessamento do cardápio sonoro escolar e da cultura midiática?

Lydia Hortélio - Muito simplesmente: BRINCANDO! De início pode não ser fácil, porque os nossos Meninos estão desacostumados a se expressar em sua verdadeira língua: o BRINCAR... Teremos então, provavelmente, um interregno desconfortável, muitos descompassos, o malestar natural do esquecimento da tradição! Mas, enfrentando o desajuste com fé e coragem, veremos chegar o re-conhecimento natural, e estabelecer-se, pouco a pouco, um convívio sensível, inteligente e generoso, movido pelas verdadeiras e infinitas formas de manifestação da CULTURA INFANTIL.

É preciso que o Professor tenha consciência de que existe uma CULTURA DA CRIANÇA, conheça o repertório da Música Tradicional da Infância, os Brinquedos cantados e os Brinquedos ritmados da Cultura Infantil contemporânea, um conhecimento com o corpo, de variadíssima linguagem de movimento, muito ao gosto dos Meninos, que nos dão a oportunidade de aprender com eles e estabelecer o vínculo necessário a uma experiência na interligação.

Da parte do Professor é muito importante desenvolver o hábito da observação constante, de uma reflexão paralela continuada, no intuito de acompanhar e perceber em 
profundidade toda a multiplicidade e riqueza, a dinâmica particular e a didática própria da CULTURA DA CRIANÇA. Assim chegaremos cada vez mais perto da mudança, da revolução que falta!

Dulcimarta Lemos Lino - 7) Se o ouvido contemporâneo tem, em grande medida, aderido ao aliciamento de um gosto ou padrão global, vinculado a interesses econômicos e comerciais, os círculos de ação educativa que vens impulsionando em todo o País podem enfrentar a exclusão da Cultura Brasileira e do espírito de brasilidade vigente nas instituições escolares? Qual a relação entre essa tendência e os projetos da Casa das Cinco Pedrinhas...?

Lydia Hortélio - Difícil, numa primeira conversa, abordar um espectro tão vasto como este que nos propomos! Mas ao longo desta entrevista teremos tocado elementos essenciais, creio eu, que convergem para questões fundamentais, apontando perspectivas e caminhos que precisam ser experimentados, discutidos e pensados adiante.

Me parece crucial descobrir uma maneira de educar que corresponda à natureza, à índole do Povo Brasileiro. Isto implica, naturalmente, em trabalho de longo hausto, mas este é um Sonho que lateja no Coração de muitos!

É preciso investir em pesquisa, no levantamento criterioso e consequente das manifestações da CULTURA POPULAR em nosso País, em toda sua vastidão, multiplicidade e riqueza, levar a efeito a realização de estudos detalhados sobre estes fenômenos, e buscar caminhos, princípios e formas de aproveitamento deste valioso patrimônio na EDUCAÇÃO. Um vasto programa, eloquente e inadiável. Tomara possamos nos unir cada vez mais e levar adiante nosso Sonho comum!

Temos uma CULTURA POPULAR vasta e diferenciada e uma CULTURA DA CRIANÇA surpreendente, graciosa, cotidiana. A ação a ser empreendida passa, inicialmente, pela CULTURA DA CRIANÇA, levando nossos Meninos a viver a MÚSICA TRADICIONAL DA INFÂNCIA, a BRINCAR..., até os 12 anos, aproximadamente. Em seguida, na adolescência, faremos a iniciação dos nossos filhos ao vasto espectro de manifestações da CULTURA POPULAR, este segundo momento de Infância, um patrimônio extraordinário que cobre todo o território nacional e oferece infinitas possibilidades de inspiração. Contamos, portanto, com um corpo de conhecimento amplo e original que se estende por todo o País, de norte a sul, de leste a oeste, variando de acordo com a composição 
étnica e as características geográficas e históricas de cada região, oferecendo elementos e perspectivas promissoras para o desenvolvimento de nossos filhos.

Seria necessário, entre as muitas providências a serem tomadas, constituir equipes formadas por Mestres da Cultura Popular, etnomusicólogos, etnodançarinos, especialistas em Teatro e Cultura Popular, Artistas, Poetas e Educadores, para trabalharmos conjuntamente, e assim chegar mais perto da magnitude de nossa empreitada: conhecer em profundidade as Manifestações Culturais do Povo Prasileiro, suas dimensões plásticas, sonoras, de movimento, cores, formas, e além... buscando aproveitá-las na EDUCAÇÃO de nossos filhos.

Quanto à contribuição da CASA DAS CINCO PEDRINHAS... neste processo, tenho a dizer que trabalhamos na Pesquisa e Documentação de CULTURA DA CRIANÇA e de CULTURA POPULAR, aproveitando os resultados destas pesquisas em discos, livros e filmes, cujo conteúdo divulgamos através de cursos, oficinas, palestras, exposições e encontros para BRINCAR. A CASA DAS CINCO PEDRINHAS... tem representação na Bahia, Minas Gerais e São Paulo, e mantém um site na internet que dá notícia de nossa ação: www.casadas5pedrinhas.com.br

Dulcimarta Lemos Lino - 8) Em diferentes encontros afirmas a importância de favorecer o exercício de ser criança, dividindo em dois grandes blocos a expressão da Cultura da Criança em Brinquedos silentes e Brinquedos sonorosos. Gismonti (2005) ${ }^{2}$ afirma que a música é um exercício de fé onde o ato de compor é um tempo de contrição e reverência ao silêncio e, esse último, disponibilidade ao inexistente. O que pensas dessa convicção?

Lydia Hortélio - Os BRINQUEDOS DE CRIANÇA são fatos culturais no espaço/tempo, cuja linguagem de movimento se configura no silêncio ou é movida através do elemento som. Tenho constatado nestes Brinquedos, inclusive, a presença inequívoca das dimensões da MÚSICA, formais e expressivas, mesmo quando o som não está presente, como no caso da Amarelinha, no Jogo de Bolinha de Gude, ou no Brinquedo de Papagaio. A estes Brinquedos gosto de chamar BRINQUEDOS SILENTES, e BRINQUEDOS SONOROSOS a aqueles, cuja linguagem de movimento é acionada através de uma parlenda, uma cantilena ou uma cantiga, como no Uni duni tê, Uma velha, muito velha, Senhora Dona Sancha, ou no Três, três passará.

\footnotetext{
${ }^{2}$ GISMONTI, Egberto. Exercício de fé. In: PERDIGAO, Andreia Bombim. Sobre o silêncio. São Paulo: Pulso, 2005.
} 
O SILÊNCIO é um mistério e um poder, o lugar onde o inexistente se revela..., como bem diz Egberto. Um espaço DENTRO, onde se ouve o Som que não tem matéria física! Creio que é a isto que Egberto se refere, quando avalia seu ofício de compositor e fala de contrição e reverência ao inexistente... Creio assistir o mesmo fenômeno entre as Crianças! Elas conhecem o SILÊNCIO, e fazem a experiência essencial da MÚSICA em seus Brinquedos, sem saber sabendo...

Dulcimarta Lemos Lino - 9) Existem diferentes modos de brincar com sons. Crianças que preferem os Brinquedos sonorosos em contraponto aos silentes? Ou elas atravessam o Brincar em sua multiplicidade expressiva? Os Brinquedos brasileiros sublinham alguma característica especial?

Lydia Hortélio - O desaparecimento da CULTURA DA CRIANÇA é um fenômeno característico do nosso tempo. O êxodo rural, o afastamento da Natureza, a vida nas cidades grandes, a falta de planejamento urbano e equipamentos inteligentes destinados à expressão e intercurso das Crianças entre elas mesmas, a televisão e os jogos eletrônicos, tudo isto vem dificultando o convívio das Crianças entre elas mesmas e desarticulando a CULTURA DA CRIANÇA, cujos pressupostos e características fundamentais apontam necessidades vitais do SER-HUMANO-AINDA-NOVO... que precisam ser respeitadas para que tenhamos Futuro!

A esta altura tornou-se inadiável a volta à NATUREZA, uma questão de política pública e um desafio para cada um de nós individualmente. Precisamos desfazer o malefício que engendramos! Num País de 8.500 .000 km2 isto não deveria ser impossível. Tudo depende da sensibilidade e inteligência que desenvolvermos, da consciência e disposição sincera em libertar o Futuro.

Em todo o Planeta a questão ecológica já não é desconhecida. Mundo afora vem se levantando um movimento cada vez mais consciente em favor da CRIANÇA, da NATUREZA, e da VIDA. É preciso que cada um de nós faça sua parte. Felizmente, contamos já com a compreensão de muitos, mesmo que atitudes mais amplas, e mais decisivas talvez, tenham que vir de outras instâncias. Mas também isto está a caminho. Em todo caso, este é o tema do nosso tempo:

\section{CRIANÇA/NATUREZA/CULTURA INFANTIL}

Em meio a toda a problemática, tenho satisfação de relatar, no âmbito de uma Pesquisa/ Documentação realizada em Serrinha, sertão da Bahia, ao longo dos últimos anos, 
registrei o número significativo de mais de 600 (seiscentos) BRINQUEDOS DE CRIANÇA, tanto Brinquedos silentes como Brinquedos com música, e 25 Histórias, muitas delas com cantigas. Este fato não será uma exceção em nosso País! Como vemos, apesar das circunstâncias controversas, a CULTURA DA CRIANÇA continua viva entre nós, e espera sua hora no Sonho e no gesto consciente de cada um de nós.

Podemos dizer sem receio de errar, contamos em nosso País com uma grande variedade de tipos e variantes de BRINQUEDOS DE CRIANÇA, inclusive os Brinquedos ritmados oriundos da CULTURA INFANTIL contemporânea, muito vivos e numerosos, cuja linguagem de movimento, altamente dferenciada, é um fenômeno expressivo da aceleração do nosso tempo e da inventividade de nossos Meninos.

Dulcimarta Lemos Lino - 10) Como percebes a relação entre a imposição da vida acelerada do mundo contemporâneo e a Infância?

Lydia Hortélio - Claro, a situação geral não é favorável às CRIANÇAS! Desgarrados da Natureza e de um convívio sensível e inteligente entre seus pares, elas se vêem subtraídas em sua força e possibilidades de expressão, cerceadas em sua graça e poder. Mas, paradoxal e felizmente, são elas que carregam o NOVO, e a esperança do Futuro! Cabe a nós abrir-lhes o caminho...

Quando as coisas estão complicadas, é porque é simples: vamos LEVAR A BRINCAR... as nossas Crianças! Em meio ao desacerto geral, é isto, justamente, o que elas mais querem, mais sabem e mais podem... Vamos restituir-lhes seu verdadeiro habitat: a NATUREZA! Ela fará ressurgir o movimento contido fundo, alto, longe, perto... E, aos poucos, veremos desdobrar-se em viço e surpresas infinitas a CULTURA DA CRIANÇA, e alcançar ALEGRIA em nossas vidas.

Dulcimarta Lemos Lino - 11) Afirmastes em palestra proferida em dezembro de 2013, na cidade de Porto Alegre, que o Brincar é um fenômeno espiritual. Para Mia Couto $(2011)^{3}$, o Brincar nos remeteria a "línguas que não sabíamos que sabíamos". Podes falar mais dessa relação entre Brincar, espiritualidade e linguagem?

\footnotetext{
${ }^{3}$ COUTO, Mia. E se Obama fosse africano? Ensaios. São Paulo: Companhia das Letras, 2011, p. 11-12.
} 
Lydia Hortélio - Creio que este tema, ou este "tom", permeia toda a nossa conversa. Claro, não se trata de religião, mas de algo indizível que pertence à essência do Ser Humano e nos inspira e anima a todos. Como bem diz Mia Couto, algo que remeteria a "línguas que não sabíamos que sabíamos...", ou como afirmou Friedrich Schiller:

O Homem só é inteiro quando brinca

E é somente quando brinca que ele existe

Na completa acepção da palavra Homem

Ou como pressagiou Fernando Pessoa em sua História do Menino Jesus, apontando

A CRIANÇA NOVA...

A CRIANÇA ETERNA...

imagem, modelo e promessa do HOMEM NOVO...

Dulcimarta Lemos Lino - 12) Hoje, para ti, qual o maior desafio no encontro entre Música, Infância e Educação?

Lydia Hortélio - Para mim, o grande desafio é administrar toda a inadequação, a imensa artificialidade em que vivemos, e que atinge nossas Crianças, necessariamente. Mas, creio como Satprem: "Não existe nada mais teimoso do que a Evolução. Ela marcha"! Então, vamos que vamos, auscultando o NOVO, e buscando a transformação...

Finalizando, gostaria de recomendar as práticas da MÚSICA TRADICIONAL DA INFÂNCIA, da MÚSICA DA CULTURA INFANTIL contemporânea, como programa ideal de iniciação à Música. Procedendo através das dimensões da CULTURA DA CRIANÇA, contamos aí com a feliz oportunidade de um aprendizado com o corpo, a alegria do convívio das Crianças entre elas mesmas, o intercurso natural e espontâneo. E de nossa parte, o cuidado de isolar do processo as implicações e cobranças do ensino/aprendizagem que antes distanciam as Crianças da verdadeira experiência musical.

Naturalmente, precisamos de um professor atento, companheiro, alegre, desafiador. Mais tarde ele poderá evocar as experiências vividas, e a partir do substrato conquistado, levar adiante o processo, propondo exercícios e estudos específicos, uma percepção mais ampla e aprofundada dos elementos da linguagem, a conscientização da dinâmica expressiva, cuidando sempre de preservar a alegria e o viço da experiência.

E como despedida de festa, quero apontar ainda as práticas da MÚSICA TRADICIONAL DA INFÂNCIA e da MÚSICA DA CULTURA INFANTIL contemporânea, 
como base de todo o processo educativo. Partindo da inteireza, ou seja, de uma vivência unificada de corpo, música, palavra, ação e o outro, estaremos favorecendo, necessariamente, o exercício de ser Criança...

Estas práticas confirmam nos Meninos seus talentos inatos, e na oportunidade do intercurso afetivo, desenvolvem a predisposição natural para o Encontro e o Humano, e levam a uma aquisição viva e fecunda da língua mãe, da língua mãe musical, pressuposto fundamental da identidade cultural, da afirmação de origem, fatores essenciais para a manifestação da multiplicidade e riqueza da cultura humana, e consequente fortalecimento do patrimônio espiritual da Humanidade.

Chegando ao término de nossa conversa, agradeço de coração a oportunidade do diálogo, deixando aqui uma fórmula que é para mim como uma senha e promessa:

CRIANÇA/NATUREZA/CULTURA INFANTIL

\section{REFERÊNCIAS}

COUTO, Mia. E se Obama fosse africano? Ensaios. São Paulo: Companhia das Letras, 2011.

GISMONTI, Egberto. Exercício de fé. In: PERDIGAO, Andreia Bombim. Sobre o silêncio. São Paulo: Pulso, 2005.

WISNIK, José Miguel. Sem receita: ensaios e canções. São Paulo: Publifolha, 2004.

Salvador, 19 de março de 2014.

Lydia Hortélio

CASA DAS CINCO PEDRINHAS...

Salvador/BA 